\title{
Sibutramine versus continuous positive airway pressure in obese obstructive sleep apnoea patients
}

\author{
A. Ferland*, P. Poirier**\# and F. Sériès*":
}

ABSTRACT: The aim of the present study was to compare the efficacy of $1 \mathrm{yr}$ of sibutramineinduced weight loss versus continuous positive airway pressure (CPAP) treatment on sleepdisordered breathing, cardiac autonomic function and systemic blood pressure in obese patients with obstructive sleep apnoea.

Subjects with a body mass index of $\geqslant 30 \mathrm{~kg} \cdot \mathrm{m}^{-2}$ without previous treatment for obstructive sleep apnoea underwent either sibutramine $(n=22)$ or CPAP $(n=18)$ treatment for $1 \mathrm{yr}$.

Sibutramine induced a $5.4 \pm 1.4 \mathrm{~kg}$ decrease in body weight compared to the CPAP group, in which no changes in anthropometric variables were observed. The CPAP treatment improved all sleep and respiratory variables, whereas sibutramine-induced weight loss improved only nocturnal arterial oxygen saturation profile. Only CPAP treatment improved night-time systolic and diastolic blood pressure and 24-h and daytime ambulatory diastolic blood pressure. Sibutramine-induced weight loss had no impact on indices of heart rate variability, whereas CPAP treatment increased daytime time domain indices.

CPAP treatment for $1 \mathrm{yr}$ had beneficial impacts on nocturnal breathing disturbances, and improved nocturnal oxygenation, night-time systolic and diastolic blood pressure, and daytime cardiac parasympathetic modulation. Sibutramine did not improve sleep-disordered breathing, systemic blood pressure or heart rate variability. There were no adverse effects, such as increment in blood pressure or arrhythmias, associated with this treatment regimen.

KEYWORDS: Continuous positive airway pressure, obesity, sibutramine, sleep apnoea, weight loss

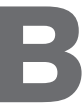
eing overweight or obese is strongly associated with a rise in the prevalence of obstructive sleep apnoea (OSA) [1]. Moreover, there is increasing evidence that OSA may be an independent factor that contributes to rising cardiovascular risk through periodic increases in sympathetic activity and blood pressure [2, 3]. Therefore, weight loss, regular physical activity and prevention of weight regain should be the first nonpharmacological recommendations for OSA patients in order to reduce the occurrence and severity of OSA, and its related morbidity [4-6].

A $10 \%$ weight loss is associated with a $50-60 \%$ decrease in the frequency of nocturnal breathing disorders and in the severity of nocturnal desaturation [5, 7]. More importantly, systemic hypertension and cardiac arrhythmias are highly prevalent in the OSA population, and may be reduced following weight loss intervention and normalisation of breathing with continuous positive airway pressure (CPAP) during sleep.
Sibutramine, which leads to an enhancement of satiety and thermogenesis by inhibiting serotonin and noradrenalin reuptake, has been shown to induce a dose-dependent weight loss ranging 2$10 \mathrm{~kg}$, thus potentiating the effects of a low-calorie diet for up to $1 \mathrm{yr}$ in obese patients $[8,9]$. Although short-term administration of sibutramine does not seem to worsen OSA [10], its noradrenergic effects may trigger arrhythmias and slightly increase blood pressure [11]. However, evidence has shown that a moderate $\sim 10 \%$ weight loss with sibutramine may improve OSA severity, without negative effects on blood pressure [12]. Thus there is an important need to compare the efficacy of this antiobesity medication with the usual CPAP treatment on changes in sleep-related breathing disorders in obese patients.

\section{MATERIALS AND METHODS}

\section{Study subjects}

Eligible participants with untreated OSA syndrome were recruited through the sleep disorder

\section{AFFILIATIONS}

*Institut universitaire de cardiologie et de pneumologie de Québec, and, Faculties of \#Pharmacy, and "Medicine, Laval University, Quebec, QC, Canada.

\section{CORRESPONDENCE}

F. Sériès

Institut universitaire de cardiologie et de pneumologie de Québec 2725 Chemin Sainte-Foy Québec

QC

G1V 4G5

Canada

E-mail: Frederic.Series@

fmed.ulaval.ca

Received:

Nov 052008

Accepted after revision:

March 292009

First published online:

April 82009 
outpatient clinic of Laval Hospital (Quebec, QC, Canada). Subjects were aged 18-65 yrs, with a body mass index (BMI) of $\geqslant 30 \mathrm{~kg} \cdot \mathrm{m}^{-2}$, or $\geqslant 27 \mathrm{~kg} \cdot \mathrm{m}^{-2}$ in the presence of other risk factors, such as controlled systemic hypertension, type 2 diabetes, dyslipidaemia and/or visceral obesity (as defined by a waist circumference of $\geqslant 102 \mathrm{~cm}$ in males and $\geqslant 88 \mathrm{~cm}$ in females). Exclusion criteria were uncontrolled systemic hypertension, defined as a blood pressure of $>145 / 90 \mathrm{mmHg}$, previous pharmacological or surgical treatment for weight loss, previous CPAP usage or the presence of severe diurnal hypersomnolence requiring immediate treatment. The main outcome measure in the present study was improvement in the apnoea/hypopnoea index (AHI). This protocol was approved by the Ethics Committee of Laval Hospital, and all patients provided written informed consent.

\section{Study design}

After having cautiously discussed their clinical condition and the different treatment strategies with one of the investigator (F. Sériès), patients chose their treatment preference (sibutramine (combination of sibutramine and calorie- and fatrestricted weight-loss diet and physical activity recommendation) or CPAP (conventional CPAP treatment and lifestyle recommendations)). This study design was chosen because it was considered that letting the patient choose their own OSA treatment would enhance their compliance with the medical treatment. It was also considered that a study design based on randomised treatment allocation would alter the evaluation of the response expected from a given treatment strategy, and would not represent the clinical situation that clinicians and patients face in a clinical setting (i.e. OSA patients who refuse CPAP as a primary treatment are encouraged to loose weight, and patients who are not convinced of the benefits/feasibility of weight loss are not the targeted population for a weight-loss programme). The first group received $10 \mathrm{mg}$ sibutramine for the first 4 weeks, at which time increasing the dosage to $15 \mathrm{mg}$ was evaluated in the case of insufficient weight loss $(<1.8 \mathrm{~kg})$ over the first month of treatment. Fasting blood samples were obtained at baseline and at 6 and 12 months for measurements of plasma glucose concentration, glycated haemoglobin $\left(\mathrm{HbA}_{1 \mathrm{c}}\right)$ level and lipid profile.

\section{Polysomnography}

Subjects underwent a conventional laboratory-based polysomnographic study at baseline and after 6 and 12 months of treatment. The measures consisted of continuous acquisition of the electroencephalogram, electro-oculogram, submental electromyogram, arterial oxyhaemoglobin saturation from transcutaneous sensing $\left(\mathrm{Sa}_{\mathrm{a}} \mathrm{O}_{2}\right)$, nasal pressure with nasal prongs connected to a pressure transducer [13], oral airflow with a thermistor, chest and abdominal movements by inductive plethysmography (Respitrace; Ambulatory Monitoring, Inc., Ardsley, NY, USA), and electrocardiogram. All variables were digitally recorded (Sandman Elite ${ }^{\mathrm{TM}}$ system; Mallinckrodt, Kenilworth, NJ, USA). Sleep-wake state and arousals were scored according to standardised criteria [14]. Subjects were asked to complete the 32-question Quebec Sleep Questionnaire (QSQ) [15], and the Epworth sleepiness scale (ESS) score was obtained [16].

\section{CPAP treatment}

CPAP treatment was initiated using manual titration of one overnight laboratory-based sleep recording. The effective pressure level chosen is the pressure level that abolishes all obstructive events (apnoea, hypopnoea, flow limitation and snoring) in every sleep stage and body position. Patients were referred to a healthcare company for choice of their CPAP devices and masks. The patient was contacted after 2 weeks in order to check subjective compliance and identify problems encountered with CPAP use. Compliance was determined using the downloadable data from the patient's CPAP device.

\section{Heart rate variability}

A 24-h Holter monitoring was performed before treatment (baseline) and during the course of therapies (Marquette Electronics, Inc., Milwaukee, WI, USA). Heart rate variability (HRV) was established through numerous indices [17], and the recording was scheduled to include the sleep recording period in order to identify apnoea-related disorders. Parameters from the spectral domain and time domain were calculated from the Holter recordings. Sub-analysis of daytime and night-time recordings was performed, as well as analysis for the full recording period [17]. In the spectral domain, power of low frequency (LF; $0.04-0.15 \mathrm{~Hz}$, which is considered an index of both sympathetic and parasympathetic activity) and high frequency (HF; 0.15-0.4 Hz, which represents most efferent vagal parasympathetic activity to the sinus node) were assessed. The LF/HF ratio, representing the sympathovagal balance, was also calculated [18]. Using time domains, normalto-normal R-R interval, SD of normal-to-normal R-R interval $(\mathrm{SDNN}), \mathrm{SD}$ of the average normal-to-normal $\mathrm{R}-\mathrm{R}$ interval calculated over a 5-min period (SDANN), square root of mean squared difference of successive normal-to-normal R-R intervals (rMSSD), number of adjacent normal-to-normal $R-R$ intervals differing by $>50 \mathrm{~ms}$ (NN50) and NN50 divided by total number of normal-to-normal $\mathrm{R}-\mathrm{R}$ intervals expressed as a percentage ( $\mathrm{pNN50)}$ were analysed. $\mathrm{rMSSD}$ and pNN50 are associated with HF and hence parasympathetic activity [17].

\section{4-h ambulatory blood pressure monitoring}

Ambulatory blood pressure monitoring (ABPM) was performed over a 24 -h period in all subjects at baseline and at $1 \mathrm{yr}$ (model 90 212; Spacelabs Healthcare, Issaquah, WA, USA) [19] in accordance with current recommendations [20, 21]. During the 24-h recording, measurements of systolic, diastolic and mean arterial blood pressure were determined using an oscillometric method, with one measurement every $15 \mathrm{~min}$ during the daytime period (06:00-22:00 h) and every $20 \mathrm{~min}$ during the night (22:00-06:00 h). Normal daytime and nighttime blood pressure and the nondipping pattern were defined according to American Heart Association recommendations for blood pressure measurements [21].

\section{Statistical analysis}

The present study was designed to have $80 \%$ power in detecting a difference in AHI of $\geqslant 15$ events $\cdot \mathrm{h}^{-1}$ between the sibutramine and CPAP groups in $60 \%$ of subjects, given that $100 \%$ of subjects in the CPAP group would show an improved AHI [22], with a two-sided unpaired t-test and type I error of $5 \%$. Thus, 20 subjects are required in the Sibutramine group in order to permit comparison with the reference group (CPAP). 
Given a $10 \%$ drop-out rate, 22 patients would need to be included in the sibutramine group. Data are presented as means \pm SD or percentages unless specified otherwise. Analysis of categorical data was carried out using the Chi-squared test or Fisher's exact test, as appropriate. Pearson's correlation coefficient was used for the analysis of associations between variables. For each outcome variable, a mixed model was performed to analyse the effects of two experimental factors, one associated with the comparison between treatments, and one linked to time (corresponding to baseline, 1 and/or 6 months and $1 \mathrm{yr}$ ) and analysed as a repeated-measure factor. Variables were logarithmically transformed where necessary to obtain a normal distribution. A p-value of $<0.05$ was considered significant. The data were analysed using the statistical package program SAS v9.1.2 (SAS Institute, Inc., Cary, NC, USA).

\section{RESULTS}

OSA patients $(n=42)$ participated in the present study. A total of $40(95.2 \%)$ patients completed the 1-yr treatment. Two patients in the sibutramine group withdrew because of loss to follow-up and adverse events. Thus 22 patients with a baseline weight of $111 \pm 14 \mathrm{~kg}$ and BMI of $36.7 \pm 4.2 \mathrm{~kg} \cdot \mathrm{m}^{-2}$ were included in the sibutramine group (table 1 ), and 18 patients received CPAP treatment and were analysed as the standard reference group. Baseline characteristics were similar between the sibutramine and CPAP groups. The weight loss after 1-yr of sibutramine treatment was, on average, $5 \mathrm{~kg}(\mathrm{p}<0.001)$, which corresponds to a relative reduction of $5 \%$ of initial weight concomitant with a $7 \%$ reduction in waist circumference $(\mathrm{p}<0.001)$, and a mean decrement in BMI of $2 \mathrm{~kg} \cdot \mathrm{m}^{-2}$ $(p=0.0005)$. The CPAP group experienced a $1.6 \mathrm{~kg}$ weight loss after 1 month of treatment $(\mathrm{p}<0.002)$, which was similar to that in the sibutramine group $(1.6 \mathrm{~kg})$. However, dietary changes were not maintained throughout the year in the CPAP group, and body weight had returned to baseline level at 6 months.

The mean AHIs of 54 and 52 events $\cdot h^{-1}$ at baseline in the sibutramine and CPAP groups, respectively, indicated severe sleep apnoea. At $1 \mathrm{yr}$, the patients assigned to CPAP showed a greater $(92 \%)$ reduction in $\mathrm{AHI}$ than did those in the sibutramine group (reduction of $40 \pm 30$ versus $3 \pm 6$ events $\cdot h^{-1}$; $\mathrm{p}<0.0001$ ) (fig. 1). It is of note that changes in AHI between baseline and $1 \mathrm{yr}$ in the sibutramine group correlated with changes in body weight $(\mathrm{r}=0.57 ; \mathrm{p}=0.006)$. Interestingly, sibutramine induced a significant increase in mean nocturnal $\mathrm{Sa}_{1} \mathrm{O}_{2}(4.8 \pm 1.7$ versus $2.2 \pm 2.5 \%$ for the sibutramine and CPAP groups, respectively; $\mathrm{p}=0.007)$, whereas $\mathrm{CPAP}$ induced the greater increase in minimum $\mathrm{Sa}_{1} \mathrm{O}_{2}(9.8 \pm 4.8$ versus $3.8 \pm 6.3 \%$ for the CPAP and sibutramine groups, respectively; $\mathrm{p}=0.0001$ ). $\mathrm{CPAP}$ significantly decreased the percentage of time spent

TABLE 1 Subject characteristics at baseline and $1 \mathrm{yr}$ in the sibutramine and continuous positive airway pressure (CPAP) groups

\begin{tabular}{|c|c|c|c|c|}
\hline & \multicolumn{2}{|c|}{ Sibutramine } & \multicolumn{2}{|c|}{ CPAP } \\
\hline & Baseline & $1 \mathrm{yr}$ & Baseline & $1 \mathrm{yr}$ \\
\hline Females/males n & \multicolumn{2}{|c|}{$3 / 19$} & \multicolumn{2}{|c|}{$2 / 16$} \\
\hline Age yrs & \multicolumn{2}{|c|}{$49 \pm 9$} & \multicolumn{2}{|c|}{$49 \pm 9$} \\
\hline Weight kg & $110.9 \pm 14.3$ & $105.5 \pm 17.4^{\star \star *}$ & $109.2 \pm 12.2$ & $109.8 \pm 14.7$ \\
\hline \multicolumn{5}{|l|}{ Blood pressure } \\
\hline $\mathrm{SBP} \mathrm{mmHg}$ & $133 \pm 8$ & $132 \pm 10$ & $128 \pm 11$ & $125 \pm 14^{\#}$ \\
\hline $\mathrm{DBP} \mathrm{mmHg}$ & $82 \pm 6$ & $84 \pm 8$ & $77 \pm 7^{\#}$ & $81 \pm 9$ \\
\hline Dippers \% & 71.4 & 60.0 & 50.0 & 61.5 \\
\hline Nondippers \% & 28.6 & 40.0 & 50.0 & 38.5 \\
\hline \multicolumn{5}{|l|}{ Heart rate beats $\cdot \min ^{-1}$} \\
\hline Total cholesterol & $4.64 \pm 0.87$ & $4.87 \pm 0.72$ & $4.84 \pm 0.83$ & $4.57 \pm 0.95$ \\
\hline Triglycerides & $1.74 \pm 1.06$ & $1.52 \pm 0.68$ & $1.76 \pm 0.71$ & $1.89 \pm 0.52$ \\
\hline HDL-C & $1.10 \pm 0.27$ & $1.27 \pm 0.33^{* \star *}$ & $1.15 \pm 0.23$ & $1.14 \pm 0.24$ \\
\hline LDL-C & $2.80 \pm 0.73$ & $2.94 \pm 0.66$ & $2.88 \pm 0.80$ & $2.55 \pm 0.82^{*}$ \\
\hline Total cholesterol/HDL-C & $4.37 \pm 0.92$ & $4.07 \pm 0.97$ & $4.31 \pm 0.92$ & $4.09 \pm 0.80$ \\
\hline \multicolumn{5}{|l|}{ Medication n (\%) } \\
\hline Antihypertensive agents & \multicolumn{2}{|c|}{$5(23)$} & \multicolumn{2}{|c|}{$6(33)$} \\
\hline Antidiabetic agents & \multicolumn{2}{|c|}{$1(5)$} & \multicolumn{2}{|c|}{$2(11)$} \\
\hline Cholesterol-lowering agents & \multicolumn{2}{|c|}{$2(9)$} & \multicolumn{2}{|c|}{$4(22)$} \\
\hline
\end{tabular}

Data are presented as mean \pm SD unless otherwise indicated. BMI: body mass index; SBP: systolic blood pressure; DBP: diastolic blood pressure; HDL-C: high-density lipoprotein-cholesterol; LDL-C: low-density lipoprotein-cholesterol. *: $p<0.05$; ${ }^{* *}: p<0.001$ versus baseline; ${ }^{*}: p<0.05$ between groups. 

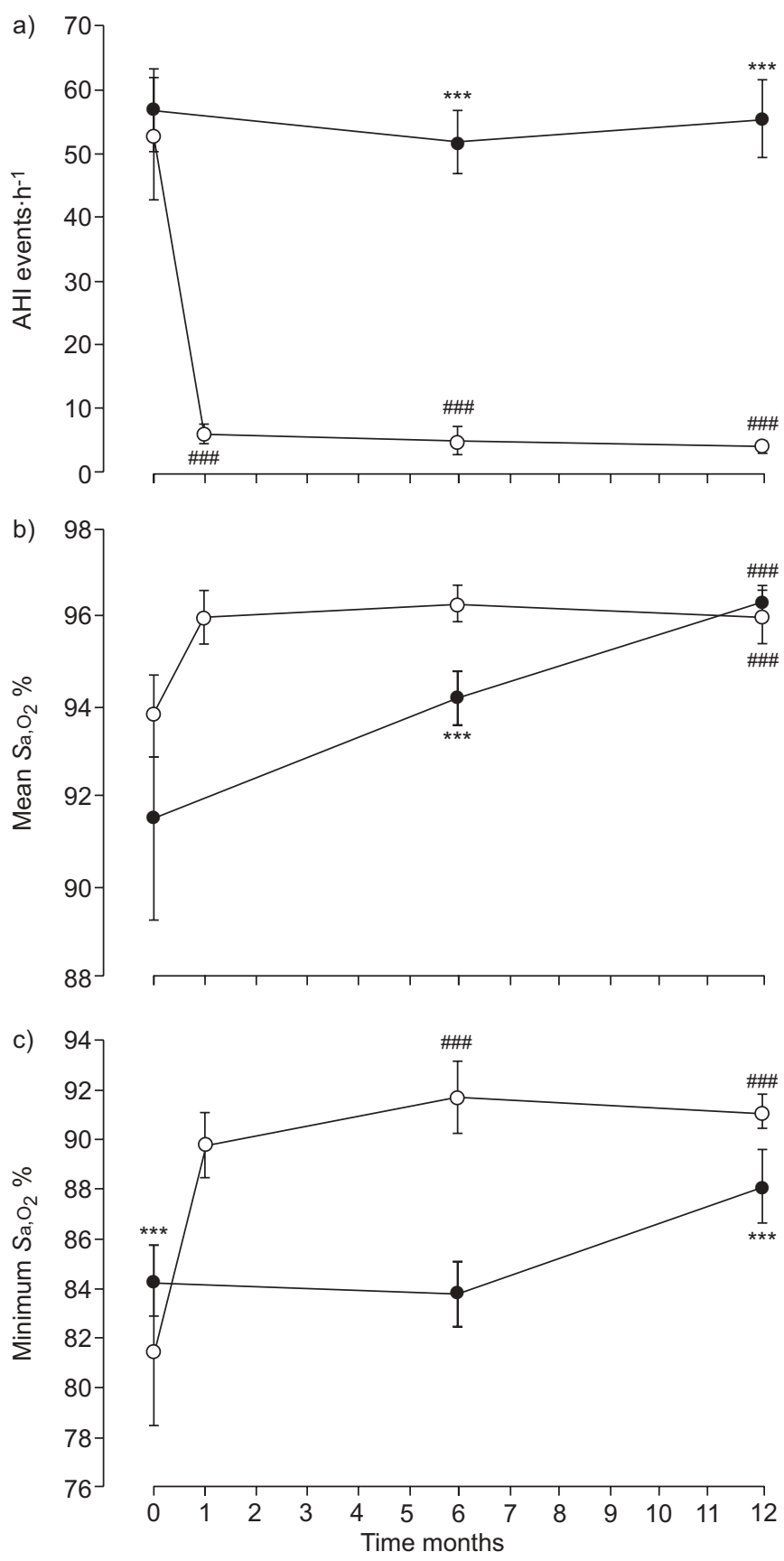

FIGURE 1. Effect of $1 \mathrm{yr}$ of continuous positive airway pressure $(O)$ and sibutramine (-) treatment on: a) apnoea/hypopnoea index (AHI); b) mean arterial oxygen saturation $\left(\mathrm{Sa}_{2} \mathrm{O}_{2}\right)$; and c) minimum $\mathrm{Sa}_{1} \mathrm{O}_{2}$. Data are presented as mean $\pm \mathrm{SD}$. ***: $p<0.001$ between groups; ${ }^{\# \# \#: ~} p<0.001$ versus baseline.

below an $\mathrm{Sa}_{1} \mathrm{O}_{2}$ of $90 \%(12.4 \pm 22.7$ to $2.6 \pm 8.8 \%$ after $1 \mathrm{yr}$; $\mathrm{p}=0.02)$, whereas no change was observed following sibutramine treatment $(8.4 \pm 18.8 \%$ to $2.1 \pm 4.2 \%$ after $1 \mathrm{yr} ; \mathrm{p}=0.08)$. The two treatments decreased the percentage of sleep in stages 1 and $2(p<0.05)$ and increased the percentage of rapid eye movement stage sleep $(\mathrm{p}<0.001)$. However, after $1 \mathrm{yr}$ of treatment, a greater improvement in sleep architecture was observed in the CPAP group $(\mathrm{p}<0.001)$. Thus the CPAP treatment improved all sleep and respiratory variables $(\mathrm{p}<0.01)$ compared with sibutramine-induced weight loss (table 2). At 12 months, subjects used CPAP for a mean of $6.6 \pm 1.6 \mathrm{~h} \cdot \mathrm{day}^{-1}$, and $89.4 \%$ used CPAP for the minimum treatment time of $4 \mathrm{~h} \cdot$ day $^{-1}$. No difference was found in subjective daytime sleepiness before and after $1 \mathrm{yr}$ of sibutramine treatment, whereas CPAP improved this parameter $(p<0.0001)$, as assessed using the ESS.

Mean heart rate decreased only in the CPAP group $(p=0.003)$, whereas minimal and maximal heart rate did not change significantly in either group compared with baseline (table 1). Weight loss induced no changes in any measures of time domain assessed from the Holter recording (table 3). The CPAP treatment enhanced daytime SDNN, SDANN $(p=0.02$; 1 year versus 1 month of treatment) and $\mathrm{pNN} 50 \quad(\mathrm{p}=0.03$; 1 year versus baseline). The $24-\mathrm{h}$ rMSSD and pNN50 parameters of HRV were higher after 1 yr of CPAP compared with 1 yr of sibutramine. Table 4 shows spectral domain indices of the Holter monitoring. Sibutramine induced no changes in LF and $\mathrm{HF}$ power or in $\mathrm{LF} / \mathrm{HF}$ ratios. CPAP treatment significantly increased the 24-h and night-time LF power data compared to the 1-month values (all $\mathrm{p}<0.01$ ). Moreover, daytime HF was higher after 1 yr of CPAP compared with $1 \mathrm{yr}$ of treatment with sibutramine. There were no changes in arrhythmias in either group.

At baseline, a nondipping pattern of blood pressure was observed in $28.6 \%$ of patients included in the sibutramine group, whereas this abnormality was present in $50.0 \%$ of CPAP patients (table 1). Mean 24-h, daytime and night-time ambulatory SBP and DBP were near normal at baseline and were comparable between groups. Sibutramine induced no changes in mean 24-h SBP and DBP over the year (129 \pm 8 versus $130 \pm 10 \mathrm{mmHg}$ for SBP and $80 \pm 6$ versus $82 \pm 8 \mathrm{mmHg}$ for DBP before and after sibutramine treatment). In addition, no significant differences were observed in daytime and nighttime mean SBP and DBP. CPAP treatment for $1 \mathrm{yr}$ improved night-time SBP and DBP $(117 \pm 7$ versus $109 \pm 13 \mathrm{mmHg}$ for SBP and $72 \pm 8$ versus $68 \pm 8 \mathrm{mmHg}$ for DBP before and after CPAP treatment; all $\mathrm{p}<0.01)$. A significant decrease was also observed in the 24-h and daytime ambulatory DBP (all $\mathrm{p}=0.04$ ). Moreover, after $1 \mathrm{yr}$ of treatment, the 24-h and daytime DBP were lower in the CPAP group compared with the sibutramine group (all $\mathrm{p}<0.01$ ).

High-density lipoprotein (HDL)-cholesterol levels increased by $15 \%$ in the sibutramine group $(\mathrm{p}<0.0001)$, and low-density lipoprotein (LDL)-cholesterol levels were reduced by $11 \%$ in the CPAP group $(p=0.02)$. Moreover, the glycated haemoglobin level was increased by $5 \%$ in the CPAP group $(p=0.04)$, whereas no changes were observed in glucose concentrations. All other biochemical parameters did not change significantly following treatment.

\section{DISCUSSION}

The present results show that CPAP treatment improved numerous sleep and respiratory variables compared to sibutramine-induced weight loss. Indeed, despite significant weight loss, the present study documents a lack of efficacy of sibutramine in improving symptoms of sleep apnoea in obese subjects with OSA. However, even if the noradrenergic effects of sibutramine could potentially account for an increase in blood pressure and triggering of arrhythmias [11], its long-term 


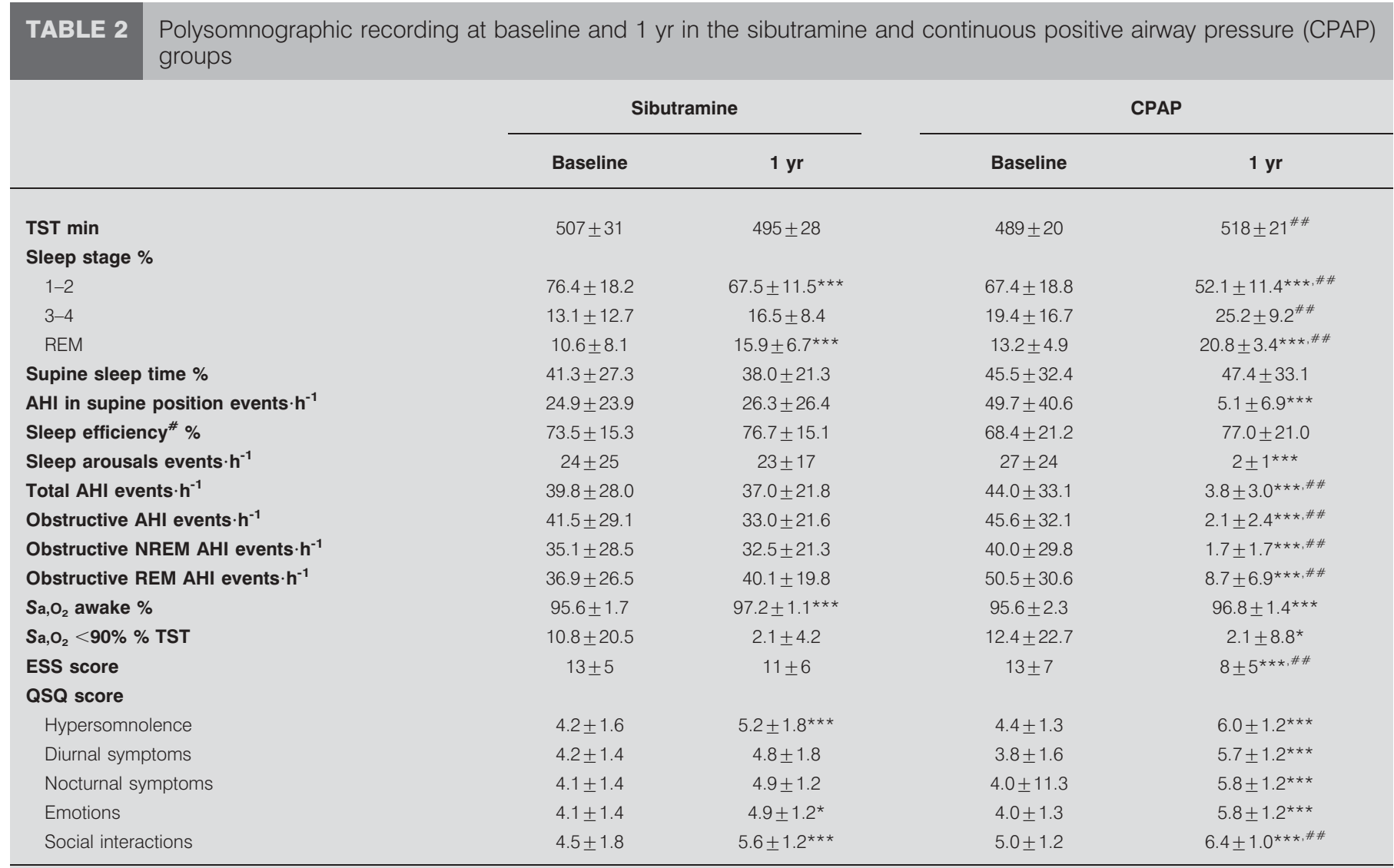

Data are presented as mean \pm SD. TST: total sleep time; REM: rapid eye movement; NREM: non-REM; AHI: apnoea/hypopnoea index; Sa, $\mathrm{O}_{2}$ : arterial oxygen saturation ESS: Epworth Sleepiness Scale; QSQ: Quebec Sleep Questionnaire. ${ }^{*}:$ TST/sleep period time. ${ }^{*}: p<0.05 ;{ }^{* * *}: p<0.001$ versus baseline; ${ }^{\# *}: p<0.01$ between groups

utilisation is not associated with worsening of sleep breathing patterns, arrhythmias and blood pressure among these patients $[12,23,24]$. This was corroborated in the present study.

Several studies have evaluated the effectiveness of weight loss for OSA treatment. Important weight loss following bariatric surgery has demonstrated the best efficiency, with improvements ranging to near-normal breathing during sleep as early as 1 month post-surgery [25-27]. Moreover, dramatic improvements (50-60\%) in nocturnal breathing disorders and in severity of nocturnal desaturation have been observed with a relatively small amount of weight loss $(<10 \mathrm{~kg})$ in other studies [5,7]. At present, the literature is sparse regarding the use of anti-obesity medication in patients with OSA. Although the efficacy of orlistat in reducing body weight in obese patients has been demonstrated in a large multicentric randomised double-blind 2-yr study [28], this medication has not yet been studied in patients with OSA. Thus it was decided to use sibutramine above other pharmacological agents since some prospective studies have shown that groups treated with sibutramine lost more weight [29]. Sibutramine appears to have a more positive effect on the reduction in central adiposity compared to orlistat [30], which is a common phenotypic feature in the presence of OSA.

A study of MARTINEZ and BASILE [10], which assessed the acute effects of sibutramine over a 1-month period without weight loss, did not find any changes in sleep architecture or severity of sleep-disordered breathing. In contrast, a 6-month treatment with sibutramine in 87 obese subjects with symptomatic OSA resulted in a $10 \%$ weight loss and improvement in OSA severity without changes in blood pressure [12]. STROBEL et al. [31] found, in a pilot uncontrolled study conducted in 13 OSA patients, that a 6-month treatment with fenfluramine, leading to a 14-kg weight loss, was associated with a dramatic decrease in the frequency of obstructive breathing disorders. It should be underlined that the long-term efficiency of these pharmaceutical treatments for weight loss in OSA patients were unknown until now, the follow-up duration of the abovementioned studies ranging 1-6 months.

Although the majority of sleep and respiratory variables were not significantly improved in the present study after a 1-yr treatment with sibutramine, the $5 \%$ weight loss had positive impacts on nocturnal mean $\mathrm{Sa}_{1} \mathrm{O}_{2}$ and $\mathrm{AHI}$. Indeed, the improvement in AHI is associated with the importance of weight loss induced with sibutramine. These findings are consistent those of YEE et al. [12], who found that the magnitude of improvement in OSA was associated with the degree of weight loss. It should be noted that subjects in the present study achieved only a modest amount of weight loss with sibutramine, but had severe sleep apnoea at baseline, which probably limited the overall improvement in OSA. CPAP treatment improved all other sleep and respiratory 


\begin{tabular}{|c|c|c|c|c|c|c|}
\hline \multirow[t]{3}{*}{ TABLE 3} & \multicolumn{6}{|c|}{$\begin{array}{l}\text { Heart rate variability indices in the time domain in } \\
\text { the sibutramine and continuous positive airway } \\
\text { pressure (CPAP) groups }\end{array}$} \\
\hline & \multicolumn{3}{|c|}{ Sibutramine ${ }^{\#}$} & \multicolumn{3}{|c|}{ CPAP } \\
\hline & Baseline & 1 month & $1 \mathrm{yr}$ & Baseline & 1 month & $1 \mathrm{yr}$ \\
\hline \multicolumn{7}{|l|}{ 24-h } \\
\hline SDNN ms & $119 \pm 38$ & $127 \pm 33$ & $126 \pm 42$ & $139 \pm 41$ & $141 \pm 46$ & $145 \pm 40$ \\
\hline SDANN ms & $107 \pm 33$ & $115 \pm 30$ & $111 \pm 42$ & $124 \pm 39$ & $128 \pm 41$ & $131 \pm 40$ \\
\hline rMSSD ms & $26 \pm 10$ & $24 \pm 11$ & $25 \pm 10$ & $30 \pm 9$ & $32 \pm 20$ & $31 \pm 11^{+}$ \\
\hline pNN50 \% & $7 \pm 6$ & $6 \pm 6$ & $6 \pm 7$ & $9 \pm 6$ & $11 \pm 12$ & $11 \pm 9^{+}$ \\
\hline \multicolumn{7}{|l|}{ Daytime } \\
\hline SDNN ms & $83 \pm 29$ & $78 \pm 24$ & $83 \pm 30$ & $85 \pm 25$ & $88 \pm 37$ & $99 \pm 30^{5}$ \\
\hline SDANN ms & $67 \pm 24$ & $59 \pm 16$ & $67 \pm 25$ & $69 \pm 21$ & $67 \pm 31$ & $79 \pm 27^{\S}$ \\
\hline rMSSD ms & $19 \pm 8$ & $19 \pm 9$ & $21 \pm 8$ & $22 \pm 7$ & $28 \pm 20$ & $26 \pm 9$ \\
\hline pNN50 \% & $3 \pm 5$ & $3 \pm 5$ & $4 \pm 5$ & $4 \pm 5$ & $8 \pm 12$ & $7 \pm 7^{\star}$ \\
\hline \multicolumn{7}{|l|}{ Night-time } \\
\hline SDNN ms & $92 \pm 26$ & $100 \pm 37$ & $92 \pm 28$ & $110 \pm 31$ & $107 \pm 44$ & $102 \pm 29$ \\
\hline SDANN ms & $60 \pm 17$ & $64 \pm 27$ & $62 \pm 19$ & $67 \pm 17$ & $65 \pm 21$ & $66 \pm 24$ \\
\hline rMSSD ms & $30 \pm 14$ & $33 \pm 15$ & $32 \pm 15$ & $40 \pm 16^{+}$ & $41 \pm 28$ & $39 \pm 14$ \\
\hline pNN50 \% & $11 \pm 11$ & $12 \pm 12$ & $11 \pm 12$ & $18 \pm 13$ & $17 \pm 18$ & $18 \pm 14$ \\
\hline
\end{tabular}

SDNN: SD of normal-to-normal R-R interval; SDANN: SD of the average normalto-normal R-R interval calculated over a 5-min period; rMSSD: square root of mean squared difference of successive normal-to-normal $R-R$ intervals; pNN50: number of adjacent normal-to-normal $R-R$ intervals differing by $>50 \mathrm{~ms}$ divided by total number of normal-to-normal $\mathrm{R}-\mathrm{R}$ intervals. ${ }^{\#:} \mathrm{n}=22$;

$\because n=18 .{ }^{*}: p<0.05$ versus baseline; ${ }^{+}: p<0.05$ between groups; ${ }^{s}: p<0.05$ versus 1 month.

variables compared to weight loss. The changes observed in the lipid profile following CPAP and sibutramine therapy might be related to weight loss or CPAP per se. Accordingly, a decline in triglyceride and increase in HDL-cholesterol are commonly observed following weight loss [26]. A study of WIRTH and KRAUSE [24] reported that sibutramine, administered for 48 weeks to a typically obese population, resulted in clinically relevant weight loss associated with an increase in HDL-cholesterol compared to placebo. Other studies also observed a decrease in LDL-cholesterol levels in both sibutramine and placebo groups, and a substantial decline in triglyceride levels in both groups [23]. In contrast, patients with moderate-to-severe OSA compliant with CPAP usage may improve their insulin secretion capacity and reduce their total cholesterol and LDL levels [32].

Previous studies have shown sibutramine to have variable effects on blood pressure and heart rate. In the present study, mean, daytime and night-time ABPM did not change throughout the year in the sibutramine group, even in the presence of significant weight loss. This stability may be due to sibutramine since this medication may have two opposing effects: 1) weight loss, inducing a decrease in blood pressure; and 2) a sympathomimetic effect, causing an increase in blood pressure. Thus the absence of a change in blood pressure with sibutramine may result from these opposite effects [33]. The present results show that CPAP therapy improves night-time SBP and DBP, and decreases the 24-h and daytime ambulatory DBP. Accordingly, a meta-analysis of BAZZANO et al. [34] provided evidence that CPAP treatment reduces blood pressure in individuals with OSA, with a mean net change of $-2.46 \mathrm{mmHg}$ in SBP and $-1.83 \mathrm{mmHg}$ in DBP among those using CPAP therapy compared to those in the control groups. No changes in autonomic cardiac modulation were observed after $1 \mathrm{yr}$ of sibutramine treatment, even if it induced a $5 \%$ weight loss. The impact of this medication on blood pressure and heart rate might have attenuated the beneficial impact of weight loss on HRV and ABPM variables. In agreement with this, BIRKENFELD et al. [11] reported that a few days on a sibutramine regimen profoundly attenuated the pressor

TABLE 4 Heart rate variability indices in the frequency domain

\begin{tabular}{|c|c|c|c|c|c|c|}
\hline & \multicolumn{3}{|c|}{ Sibutramine ${ }^{\#}$} & \multicolumn{3}{|c|}{ CPAP } \\
\hline & Baseline & 1 month & $1 \mathrm{yr}$ & Baseline & 1 month & $1 \mathrm{yr}$ \\
\hline \multicolumn{7}{|l|}{ 24-h } \\
\hline Ln LF ms ${ }^{2}$ & $5.83 \pm 0.90$ & $5.93 \pm 1.01$ & $5.88 \pm 0.80$ & $6.05 \pm 0.97$ & $5.66 \pm 1.22$ & $6.21 \pm 0.67^{* *}$ \\
\hline $\mathrm{Ln} \mathrm{HF} \mathrm{ms}^{2}$ & $4.35 \pm 0.93$ & $4.48 \pm 1.08$ & $4.46 \pm 0.87$ & $4.82 \pm 0.95$ & $4.50 \pm 1.09$ & $5.00 \pm 0.77$ \\
\hline LF/HF & $4.91 \pm 2.34$ & $4.94 \pm 2.93$ & $4.55 \pm 2.51$ & $3.74 \pm 1.83$ & $3.54 \pm 1.84$ & $3.80 \pm 1.63$ \\
\hline \multicolumn{7}{|l|}{ Daytime } \\
\hline Ln LF $\mathrm{ms}^{2}$ & $5.53 \pm 0.94$ & $5.68 \pm 1.05$ & $5.61 \pm 0.86$ & $5.67 \pm 1.09$ & $5.42 \pm 1.19$ & $5.96 \pm 0.64$ \\
\hline $\mathrm{Ln} \mathrm{HF} \mathrm{ms}^{2}$ & $3.85 \pm 1.06$ & $3.97 \pm 1.15$ & $3.97 \pm 0.95$ & $4.20 \pm 1.05$ & $4.22 \pm 1.09$ & $4.58 \pm 0.81^{\# \#}$ \\
\hline $\mathrm{LF} / \mathrm{HF}$ & $6.33 \pm 3.28$ & $6.65 \pm 3.89$ & $5.92 \pm 3.97$ & $4.79 \pm 2.09$ & $3.89 \pm 2.52$ & $4.59 \pm 2.26$ \\
\hline \multicolumn{7}{|l|}{ Night-time } \\
\hline $\mathrm{Ln} L F \mathrm{~ms}^{2}$ & $6.20 \pm 0.99$ & $6.37 \pm 1.10$ & $6.21 \pm 0.87$ & $6.48 \pm 0.99$ & $5.99 \pm 1.31$ & $6.52 \pm 0.79 * *$ \\
\hline $\mathrm{Ln} \mathrm{HF} \mathrm{ms}^{2}$ & $4.91 \pm 1.14$ & $5.23 \pm 1.11$ & $5.09 \pm 0.97$ & $5.45 \pm 0.98$ & $4.90 \pm 1.11$ & $5.46 \pm 0.84$ \\
\hline $\mathrm{LF} / \mathrm{HF}$ & $4.32 \pm 2.61$ & $3.79 \pm 2.42$ & $3.50 \pm 1.90$ & $3.32 \pm 2.45$ & $3.27 \pm 1.57$ & $3.31 \pm 1.77$ \\
\hline
\end{tabular}

CPAP: continuous positive airway pressure; LF: low frequency; HF: high frequency. ${ }^{*}: n=22 ;{ }^{\bullet}: n=18 .{ }^{* *}: p<0.01$ versus 1 month; ${ }^{\# \#}: p<0.01$ between groups. 
response to sympathetic stimuli through a clonidine-like sympatholytic effect. As reported elsewhere [35-37], the analysis of daily fluctuations in HRV in the CPAP group showed that improvements in indices in the time domain were accompanied by a significant decrease in mean heart rate.

Although the present participants chose between the weight loss programme and conventional CPAP treatment, the sibutramine and CPAP groups were remarkably similar at baseline. It was felt that this study design would best reflect usual clinical practice, and is a key issue in this study being considered clinically valuable. After confirmation of the diagnosis of OSA, patients were presented with the different treatment management strategies, which included weight loss and CPAP. CPAP might not be selected as a primary treatment in a significant number of patients. Similarly, although weight loss is always presented as an important component of the treatment strategy, some patients do not feel that they would be able to stick with the dietary and exercise requirements required for significant weight loss. It is of interest that the PREFER study was a randomised controlled clinical trial testing treatment preference in subjects assigned to one of two calorie- and fat-restricted diets [38]. They found that choosing treatment preference was probably the most influential factor in determining adherence to the diet treatment, and suggest that it would be important to use this concept with those who are willing to make significant changes in their lifestyle. Therefore, we feel that sleep apnoea treatment must be tailored according to the willingness of patients to comply with specific requirements, making the patient's treatment choice a very important issue in establishing a treatment plan, as it should be in clinical practice. This is firmly supported by the very high compliance with treatment that was observed in each treatment arm (91.7 and $100.0 \%$ after $1 \mathrm{yr}$ for sibutramine and CPAP treatment, respectively). Although entirely speculative, the present results suggest that sibutramine combined with conventional CPAP therapy is probably safe for optimised weight loss in the management and treatment of OSA in obese patients, since there were no changes in blood pressure and arrhythmia associated with this treatment regimen. This underlines the need for randomised controlled trials comparing sibutramine in addition to CPAP to CPAP alone in patients with severe sleep apnoea. Conversely, in patients with mild-tomoderate sleep apnoea, weight loss therapy might be more effective in reducing the AHI. Therefore, in strongly motivated subjects free of clinically significant comorbid conditions and/ or clinical symptoms (i.e. excessive daytime sleepiness), druginduced weight loss could potentially represent a first-line treatment strategy, and this should be assessed in adequately designed clinical trials.

In conclusion, the present results show that $1 \mathrm{yr}$ of CPAP treatment has a beneficial impact on OSA in improving nocturnal oxygenation, night time SBP and DBP, and daytime indices of HRV. Conversely, despite significant weight loss, sibutramine did not modify OSA, HRV or blood pressure. Nevertheless, these results suggest that sibutramine is safe for the optimisation of weight loss in the management and treatment of OSA in obese patients, since there was no change in blood pressure or arrhythmia associated with this treatment regimen.

\section{CLINICAL TRIALS}

This study is registered at ClinicalTrials.gov (trial number NCT00729963).

\section{SUPPORT STATEMENT}

A. Ferland is a Canadian Diabetes Association (Toronto, ON, Canada) postdoctoral fellow. P. Poirier is a clinician-scientist of the Fonds de la Recherche en Santé du Québec (FRSQ; Montreal, QC, Canada). F. Sériès is a national researcher of the FRSQ. The funding source played no role in the design, collection, analysis or interpretation of the data, or in the decision to submit the study for publication.

\section{STATEMENT OF INTEREST}

A statement of interest for this study can be found at www.erj. ersjournals.com/misc/statements.dtl

\section{REFERENCES}

1 Vgontzas AN, Tan TL, Bixler EO, et al. Sleep apnea and sleep disruption in obese patients. Arch Intern Med 1994; 154: 1705-1711.

2 Narkiewicz K, van de Borne PJ, Montano N, et al. Contribution of tonic chemoreflex activation to sympathetic activity and blood pressure in patients with obstructive sleep apnea. Circulation 1998; 97: 943-945.

3 Somers VK, Dyken ME, Clary MP, et al. Sympathetic neural mechanisms in obstructive sleep apnea. J Clin Invest 1995; 96: 1897-1904.

4 Poirier P, Giles TD, Bray GA, et al. Obesity and cardiovascular disease: pathophysiology, evaluation, and effect of weight loss. An update of the 1997 American Heart Association Scientific Statement on Obesity and Heart Disease from the Obesity Committee of the Council on Nutrition, Physical Activity, and Metabolism. Circulation 2006; 113: 898-918.

5 Peppard PE, Young T, Palta M, et al. Longitudinal study of moderate weight change and sleep-disordered breathing. JAMA 2000; 284: 3015-3021.

6 Young T, Palta M, Dempsey J, et al. The occurrence of sleepdisordered breathing among middle-aged adults. N Engl J Med 1993; 328: 1230-1235.

7 Smith PL, Gold AR, Meyers DA, et al. Weight loss in mildly to moderately obese patients with obstructive sleep apnea. Ann Intern Med 1985; 103: 850-855.

8 McNeely W, Goa KL. Sibutramine. A review of its contribution to the management of obesity. Drugs 1998; 56: 1093-1124.

9 James WP, Astrup A, Finer N, et al. Effect of sibutramine on weight maintenance after weight loss: a randomised trial. Lancet 2000; 356: 2119-2125.

10 Martinez D, Basile BR. Sibutramine does not worsen sleep apnea syndrome: a randomized double-blind placebo-controlled study. Sleep Med 2005; 6: 467-470.

11 Birkenfeld AL, Schroeder C, Pischon T, et al. Paradoxical effect of sibutramine on autonomic cardiovascular regulation in obese hypertensive patients - sibutramine and blood pressure. Clin Auton Res 2005; 15: 200-206.

12 Yee BJ, Phillips CL, Banerjee D, et al. The effect of sibutramineassisted weight loss in men with obstructive sleep apnoea. Int $J$ Obes (Lond) 2007; 31: 161-168.

13 Sériès F, Marc I. Nasal pressure recording in the diagnosis of sleep apnoea hypopnoea syndrome. Thorax 1999; 54: 506-510.

14 EEG arousals: scoring rules and examples: a preliminary report from the Sleep Disorders Atlas Task Force of the American Sleep Disorders Association. Sleep 1992; 15: 173-184.

15 Lacasse Y, Bureau MP, Sériès F. A new standardised and selfadministered quality of life questionnaire specific to obstructive sleep apnoea. Thorax 2004; 59: 494-499. 
16 Johns MW. A new method for measuring daytime sleepiness: the Epworth Sleepiness Scale. Sleep 1991; 14: 540-545.

17 Task Force of the European Society of Cardiology and the North American Society of Pacing and Electrophysiology, Heart rate variability. Standards of measurement, physiological interpretation, and clinical use. Eur Heart J 1996; 17: 354-381.

18 Poirier P, Hernandez TL, Weil KM, et al. Impact of diet-induced weight loss on the cardiac autonomic nervous system in severe obesity. Obes Res 2003; 11: 1040-1047.

19 Bieniaszewski L, Staessen JA, Thijs L, et al. Ambulatory blood pressure monitoring in clinical trials. Ann N Y Acad Sci 1996; 783: 295-303.

20 O'Brien E, Asmar R, Beilin L, et al. European Society of Hypertension recommendations for conventional, ambulatory and home blood pressure measurement. J Hypertens 2003; 21: 821-848.

21 Pickering TG, Hall JE, Appel LJ, et al. Recommendations for blood pressure measurement in humans and experimental animals. Part 1: blood pressure measurement in humans: a statement for professionals from the Subcommittee of Professional and Public Education of the American Heart Association Council on High Blood Pressure Research. Circulation 2005; 111: 697-716.

22 Barvaux VA, Aubert G, Rodenstein DO. Weight loss as a treatment for obstructive sleep apnoea. Sleep Med Rev 2000; 4: 435-452.

23 Derosa G, Cicero AF, Murdolo G, et al. Comparison of metabolic effects of orlistat and sibutramine treatment in type 2 diabetic obese patients. Diabetes Nutr Metab 2004; 17: 222-229.

24 Wirth A, Krause J. Long-term weight loss with sibutramine: a randomized controlled trial. JAMA 2001; 286: 1331-1339.

25 Davila-Cervantes A, Dominguez-Cherit G, Borunda D, et al. Impact of surgically-induced weight loss on respiratory function: a prospective analysis. Obes Surg 2004; 14: 1389-1392.

26 Grunstein RR, Stenlof K, Hedner JA, et al. Two year reduction in sleep apnea symptoms and associated diabetes incidence after weight loss in severe obesity. Sleep 2007; 30: 703-710.

27 Varela JE, Hinojosa MW, Nguyen NT. Resolution of obstructive sleep apnea after laparoscopic gastric bypass. Obes Surg 2007; 17: $1279-1282$.
28 Sjoström L, Rissanen A, Andersen T, et al. Randomised placebocontrolled trial of orlistat for weight loss and prevention of weight regain in obese patients. Lancet 1998; 352: 167-172.

29 Gursoy A, Erdogan MF, Cin MO, et al. Comparison of orlistat and sibutramine in an obesity management program: efficacy, compliance, and weight regain after noncompliance. Eat Weight Disord 2006; 11: e127-e132.

30 Kamel EG, McNeill G, Van Wijk MC. Change in intra-abdominal adipose tissue volume during weight loss in obese men and women: correlation between magnetic resonance imaging and anthropometric measurements. Int J Obes Relat Metab Disord 2000; 24: 607-613.

31 Strobel RJ, Lewin D, Rosen RC, et al. Fenfluramine hydrochrorideassisted weight loss in obstructive sleep apnea syndrome. Am Rev Respir Dis 1994; 149: Suppl. 1, A495.

32 Cuhadaroglu C, Utkusavas A, Ozturk L, et al. Effects of nasal CPAP treatment on insulin resistance, lipid profile, and plasma leptin in sleep apnea. Lung 2009; 187: 75-81.

33 Haynes WG, Egri Z. Sibutramine and the sympathetic nervous system in obese humans. Clin Auton Res 2005; 15: 189-192.

34 Bazzano LA, Khan Z, Reynolds K, et al. Effect of nocturnal nasal continuous positive airway pressure on blood pressure in obstructive sleep apnea. Hypertension 2007; 50: 417-423.

35 Khoo MC, Kim TS, Berry RB. Spectral indices of cardiac autonomic function in obstructive sleep apnea. Sleep 1999; 22: 443-451.

36 Limphanudom P, Chierakul N, Pinyopattarakul N, et al. Recovery of heart rate variability in patients with moderate to severe obstructive sleep apnea after 6-month continuous positive airway pressure treatment. J Med Assoc Thai 2007; 90: 1530-1535.

37 Gula LJ, Krahn AD, Skanes A, et al. Heart rate variability in obstructive sleep apnea: a prospective study and frequency domain analysis. Ann Noninvasive Electrocardiol 2003; 8: 144-149.

38 Burke LE, Styn MA, Steenkiste AR, et al. A randomized clinical trial testing treatment preference and two dietary options in behavioral weight management: preliminary results of the impact of diet at 6 months - PREFER study. Obesity 2006; 14: 2007-2017. 